\title{
The Electronic Campus: The Impact of the Scholar's Workstation Project on the Libraries at Brown
}

\author{
Barbara B. Moran, Thomas T. Surprenant, \\ and Merrily E. Taylor
}

The academic library has traditionally served as the centralized storehouse of information for the academic community, but inevitably its functions will change as more campuses are "wired" and as students and faculty have access to information through individual computer workstations linked in a local campus network for scholarly communication. This case study describes the Scholar's Workstation project, a campuswide computerization project at Brown University, and assesses the effects, to date, of that project on the institution's libraries. Suggestions are provided to other libraries whose institutions are beginning to explore the possibility of a similar venture.

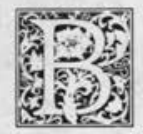

rown University in Providence, Rhode Island, has embarked on a major project to expand and integrate its computing, communication, and information systems. As a result the school has received a great deal of publicity and has been touted in the literature of higher education as an example of a liberal arts university that is being transformed from a traditional campus into an electronic one. Obviously, a transformation of this magnitude will affect all segments of the university, including the library. The purpose of this research was to look specifically at the impact of the campuswide computerization project on the role and operation of the academic libraries at Brown.

The researchers' interest in the Brown experiment began in the summer of 1984, when the Council on Library Resources sponsored an Association of Research Libraries' Institute on Research Libraries for Library Science Faculty. At the institute there were many discussions about the role of the academic research library in a changing technological and educational environment. In particular, the group speculated about how the crucial role the academic library plays in scholarship and instruction could be maintained in an era of electronic information.

Although writers of library literature have dealt extensively with the effects of applying computer technology to library processes and services, little has been written about the effects of campuswide computer technology on the academic library. The lack of research on the topic is not surprising since it was not until the

Barbara B. Moran is Assistant Professor at the School of Library Science, University of North Carolina at Chapel Hill. Thomas T. Surprenant is Director at the Graduate School of Library and Information Studies, Queens College, City University of New York. Merrily E. Taylor is University Librarian at Brown University.

Research was made possible by a Faculty/Librarian Cooperative Research Grant provided by the Council on Library Resources. 
last two or three years that institutions began to develop campuswide networks for information sharing. There has not been sufficient time to study how this innovation is changing the lives of students and faculty, and, possibly, the very nature of higher education. The "wiring" of campuses will have a profound impact on academic libraries, and for the first time it is possible to begin to gauge that effect.

The three authors of this report felt that it was critical to assess the place and role of the academic library in the electronic campus of the future. Since Brown University was in the process of undergoing an evolution towards such a campus, it provided a rare opportunity for such a study. Brown, Carnegie Mellon University (CMU), and the Massachusetts Institute of Technology (MIT) have been called the "Star Wars" universities-the high-tech innovators in a transformed world of higher education. Together, these three institutions have invested nearly $\$ 200$ million in information technology for instructional purposes over the last few years. ${ }^{1}$ Brown provides a particularly interesting example of this technological transformation since it, unlike CMU and MIT, is not a technological institution but primarily a liberal arts college, an orientation more typical of the vast majority of institutions of higher education in the United States. Brown also has a tradition of emphasizing humanistic education and of considering the library central to the education process. Thus, Brown could provide a scenario of what may happen to many academic libraries in the near future. Studying the process that is going on at Brown would provide information about the effects of campuswide computerization of libraries, particularly information in the broad area of institutional planning and management, which should be useful to other librarians. As a result, they should be able to make more informed decisions as their own institutions move toward incorporating more information technology. A grant proposal to study the Brown experiment was submitted to the Council on Library Resources and was approved. This article summarizes the major findings of that research.

\section{BROWN UNIVERSITY}

It is not surprising that Brown University is one of the sites of the latest innovation in higher education. In the past, Brown has been a pioneer in other educational developments. In the 1800 s under the leadership of Francis Wayland, Brown was one of the first universities to permit students to take elective courses. Then, in the early 1970 s, the school was at the forefront of American curriculum reform again, adopting a flexible undergraduate curriculum that is still proving to be very attractive.

By the late 1970s Brown was experiencing the same problem as many other institutions: a computer capacity that was increasingly inadequate to meet student and faculty demands. Although the mainframe computer was frequently upgraded, these upgrades never permitted the school to meet or stay ahead of demand. In 1983, Brown began an ambitious, long-term undertaking called the Scholar's Workstation project. The goal was to experiment with, shape, and evaluate new types of computer and communication tools that might have a profound effect on future education and scholarship.

The keystone of the project was the development of an integrated network of campus computers that could be used for a wide variety of teaching and research purposes. Individual workstations were proposed that would be more powerful than most existing personal computers with a capacity of a million pixels of information on the screen, a million processes per second, and a million bytes of storage.

The original plan for the Scholar's Workstation project envisioned 2,000 workstations on campus by the end of 1984. By 1987, there would be 10,000 workstations including those located in faculty homes and Brown-affiliated hospitals. ${ }^{2}$ These powerful microcomputers would be connected into local networks that in turn would be connected into the university network, BRUNET, a broadband, coaxial cable communications system that already linked many of the campus buildings. The workstations, which were expected to affect almost all aspects 
of teaching and learning at Brown, would include such functions as computation, word processing, information retrieval, data analysis, computer graphics, network communications, and library access. The result of the Scholar's Workstation project would be a campus with decentralized computing resources, but one that would be integrated electronically with students, faculty, staff, and resources tied together in a functioning "wired university."

The Institute for Research in Information and Scholarship (IRIS) was established at Brown in 1983 to oversee the Scholar's Workstation project and to serve as a self-supporting, umbrella organization. Its primary purpose was to coordinate research and experimentation in the development of innovative use of information and communication technologies in education and scholarship. IRIS was also charged with the task of evaluating and analyzing the impact of the project on both individuals and the institution. The purpose of IRIS was pivotal in the Scholar's Workstation project. When he announced the establishment of the institution, President Howard Swearer stated:

From IRIS will stem the technical and creative impulses that will drive and focus a broad range of experiments. Information developed by IRIS will show us how the new generation of computing can best serve faculty and students in the humanities as well as in the sciences, preserving our strong liberal arts tradition. ${ }^{3}$

To make this project a reality, Brown had to rely heavily on outside funding. Being a pioneer is always risky, but to attract large amounts of outside money, it is advantageous to be among the first working on a project, as funding agencies are more willing to invest. The type of project that Brown envisioned was especially attractive to corporate sponsors because it held out the promise of eventual commercial viability. If a Scholar's Workstation could be produced that fulfilled the expectations of its proponents at Brown, it should also be extremely attractive for eventual marketing at other campuses.

Brown obtained a great deal of support for its efforts to bring computerization to its campus. In May 1983, the university announced the gift of fifty LISA systems from Apple and thirty systems from Apollo. Apple also agreed to provide substantial discounts on purchases of additional computers. ${ }^{4}$ In July 1983, major support from IBM was announced. The total value was estimated to be about $\$ 15$ million over three years, the largest single corporate partnership in the history of the university. IBM's participation included both a grant and support for a Brown-IBM research and development partnership.

\section{RESEARCH QUESTIONS}

Brown was obviously gearing up for major changes on campus. The authors wanted to be on campus as early as possible to see what the effects of technological change would be on the library. Specifically, information was sought on the following research questions:

(1) To what extent are the plans for the Scholar's Workstation operational at Brown?

(2) How does the library fit into the system and, specifically, how is the library being drawn into the teaching/learning process?

(3) What are the basic problems that have been encountered in both the planning and implementation of the project?

(4)What is the perceived and the actual role of the library? Is it central, tangential, or bypassed?

(5)What will the widespread use of personal computers do to the use of traditional printed materials found in libraries?

(6)Will the funding of an electronic campus present a threat to the library's budget?

(7) What elements can be identified as critical to the proper integration of the library into the electronic campus?

(8) What can be learned from the experience of Brown that can be transferred to other campuses?

\section{RESEARCH METHODS}

To gather the information needed to provide answers to these questions, the researchers decided to use a case study approach. The case study method was felt to be the only valid approach despite the limitation of not being generalizable to a 
larger population. Using this method, the researchers would be able to describe what had gone on at Brown to date, assess the impact of the project, and then, by means of additional studies, be able to track future developments.

By necessity, the research was exploratory, but the researchers hoped to gather baseline information that might provide the foundation for future studies in this area. The research would be enhanced by the presence on the team of one individual who was directly associated with Brown and two who had no connections with it. The inside member would be invaluable in terms of providing access to key individuals, supplying the outsiders with basic information and documentation, verifying data, and identifying crucial elements in the environment. Finally, as an ongoing participant in the process, the insider would be able to keep the others abreast of developments and changes. On the other hand, the outsiders could supply objectivity through their lack of vested interest in the process at the university. In addition, the individuals to be interviewed would be more likely to be open with outside interviewers because there was no political liability associated with speaking frankly.

Extensive background reading was done to prepare for the interviews. A great deal of information was available from Brown about the Scholar's Workstation project, and, in addition, access to internal documents and memoranda pertaining to the project was provided. The researchers also read the published literature relating to the project, although that literature is, to date, rather scant.

Two separate interview schedules were drawn up: one to be used with the university administrators and faculty and a second to be used with librarians. The questions on the first set were broadly focused on the implementation of the Scholar's Workstation project and its likely impact on the campus in general and the library in particular, while the questions on the second set were focused more narrowly on is- sues relating to the Brown University libraries. After the question sets were drawn up, they were pretested and revised.

In September 1985, the researchers met on the Brown campus to plan the research and to select the sample of individuals to be interviewed. The sample consisted of two sectors: (1) individuals chosen randomly, and (2) key individuals who were included because of their importance to the project. In October 1985, the two outside researchers returned to Brown for the actual interviewing process. All interviews were done over the course of five days, and both of the outside researchers were present for most of the interviews.

Thirty people were interviewed; the interviews ranged in length from thirty minutes to two hours with most averaging about an hour. All of the individuals except one gave permission for the interviews to be tape recorded. The interviews were held with a cross-section of university administrators, faculty, library administrators, and librarians, and one student.* All were extremely open about the process of implementing the Scholar's Workstation project. No one refused to be interviewed, and the researchers were impressed by the frankness of everyone in their appraisals of both the strengths and the weaknesses of the project.

At the close of each day, the researchers met, recapitulated the day's events, and discussed plans for the next day. In between interviews, as many campus facilities as possible were visited. After the week of interviewing, the taped interviews were transcribed. The data were organized, key issues were identified, and the report was prepared.

\section{General}

\section{RESULTS}

The outside researchers arrived at Brown with some expectations of what would be found on campus. From the published reports about the project the researchers expected to find a network of

*Due to lack of time, more interviews with students could not be scheduled as originally planned. 
fully functioning workstations, a wired campus, and workstations being used individually and in classrooms by both faculty and students. What was actually found was different. As with almost all complex plans, delays and slippage had occurred, and Brown had not progressed as far as it had anticipated. The timetable for implementation had been far too ambitious. Most disappointing was the fact that the Scholar's Workstations had not yet been installed. There was at least one prototype machine on campus at that time, but the prototype could be viewed only by individuals who had signed nondisclosure agreements with IBM. Most of the people interviewed had not yet seen the prototype and thus did not know how well it met prior expectations.

The campus was almost completely wired with plans to finish wiring the dorms by the end of summer 1986. Although the campus is considered wired, the wiring goes only to the outside of the buildings, and individual departments have to pay for the T-box connections and the wiring inside the buildings. There were still some departments, especially in the humanities, that had not brought the wiring inside their buildings.

It was quickly discovered that Brown had already scaled down its expectations about the project. No one at Brown was talking about 10,000 workstations; the expectation was that the university would begin with a small number of workstations and acquire 500 at most. The costs of the original plan had been much higher than expected, and the realization of these costs had applied a brake to the hopes of acquiring a larger number. There was also a greater acceptance of a mix of computer technologies on campus than originally planned, and the realization that the power of the Scholar's Workstation was far more than was necessary for many users.

The interviews made it clear that Brown administrators, faculty, and librarians on all levels were divided in their opinions about the Scholar's Workstation project. They were split in their expectations, their knowledge, and their acceptance of the project. With one major exception though, all the individuals interviewed were in favor of the concept, although the degree of acceptance varied.

Where disagreement arose, it almost always centered on the overall cost of the project. The grant from IBM has covered most of the initial costs to the university, but the grant is drawing to an end, and the cost of the project soon must be assumed by the university. The costs have greatly escalated from the original estimates, and the fact that the expenses of the project will soon have to be covered as a part of the regular operating budget has caused many early proponents to worry that Brown may have undertaken more than it can afford. As in all universities, especially private universities, there are many competing demands on the budget, including demands for increased faculty salaries and more generous student aid. Although Brown is considered to be a wealthy university, the researchers were reminded often that its endowment is the smallest of any of the Ivy League schools. It has become obvious at Brown that the funds needed to support the workstation project could consume ever-larger portions of the budget to the detriment of other areas.

No one seems to have much factual information about the actual costs of the project in the future. Even people who are in charge of budgeting do not have firm figures. There are rough estimates of the percentage of the budget computerization may require, but nothing concrete. Everyone interviewed admitted that budgeting for the project in the future was going to be extremely difficult and that not enough had been done to think through the process. But this uncertainty seemed to be accepted with equanimity by the senior administrators interviewed. One of them remarked:

Brown is absolutely a tightrope act. We all walk on high wires around here. The only thing that is less comfortable than this is not having this attention, not having this activity, and not doing this at all. So you live with one set of anxieties or another and we have chosen to live with these.

There was a certain amount of impatience and disillusionment at all levels, 
which was not surprising, considering the scope of the original plans and what has been realized to date. There was also a widespread awareness that the problems of developing the hardware had been much greater than expected. Many people were also concerned about the software to be used, especially the courseware that would have to be developed if the workstations were to be used as originally planned. Among the faculty there were fears expressed that the university had no way of rewarding faculty for the time and the effort that would need to be invested in production of courseware. Because Brown's instructional budget is already so large, there was little hope of faculty receiving released time to work on such projects.

Despite the concerns of many, there is still an air of optimism on campus about the project. Although there are few who believe that the original objectives of the project will ever be met, most of the people interviewed still believe in its ultimate worth. Opposition to the workstation project certainly exists on campus, some of it quite bitter. Estimates of the opposition ranged from 5 percent to 50 percent of the faculty. The most likely estimate seems to be 10 percent to 20 percent. These opponents feel that the workstations are consuming money that could be better used for other educational purposes. Detractors say that the whole mission of the university has been skewed by this project and that the institution is being transformed from a liberal arts institution into "Brown Tech."

Although the actual workstations are not in operation on campus, the Brown environment has changed drastically from what it was prior to the planning for this project. Computer technology is highly visible on the campus. Every departmental office and almost every faculty office that was seen had at least one computer terminal in it. People's work habits have changed, and most of the faculty and staff are utilizing existing computer technology in their jobs. Many students are arriving on campus with computers and even more are purchasing them in the Brown "Computer Store." Although the Scholar's Workstations were not opera- tional in fall 1985, Brown did have a fully installed campus network with over 3,200 personal computers of various types connected to it. Brown is a "wired" campus now, even though the development of the Scholars' Workstations is far behind the original schedule.

\section{Ways the Implementation Could Have Been Improved}

Other institutions contemplating a similar project to the one at Brown could learn a great deal from Brown's experience. In retrospect, it is easy to point out some things that might have made the process of computerizing the campus at Brown go more smoothly. The most obvious one of these would have been greater attention paid to communication between the people in charge of the Scholar's Workstation project and the rest of the university community. Although there was some communication about the project from its inception, among the individuals interviewed almost all felt that communication between IRIS and the rest of the campus had been inadequate.

The second major flaw in Brown's implementation involved building up expectations that could not be met. There were gross underestimates of the time and cost involved in making the project operational. Part of this deficiency stemmed from the fact that Brown decided not to go with off-the-shelf technology but, instead, entered a partnership with a corporate entity to produce its own. Brown thus had to rely on its partner, IBM, to maintain its schedule. By October 1985, the project was at least sixteen months behind schedule because the technology had not moved as fast as most people had projected. The cost escalations also had resulted from contracting for undeveloped products. Because of the uncertainties involved and the subsequent downscaling of the plans, the process was described as one where "people's expectations were raised to very high levels initially and then they had to be damped back."

Another shortcoming in the process at Brown stemmed from the fact that the individuals who had the most influence in the project operated, at least in the beginning, under the assumption that everyone 
at Brown would be uniformly in favor of the project. Thus, they provided inadequate preparation for readying the rest of the campus for the changes that would ensue and failed to enlist support in advance of the project. None of the downside risks involved in entering the project seem to have been adequately thought through and were certainly not publicized. As one administrator said, "We committed first and asked searching questions later." This administrator believes that if the searching questions had been asked the project would still have been undertaken, but the school would have been spared some of the surprises it has had to endure in the process.

It was explained that the project was undertaken hastily because the opening opportunity with IBM did not permit more time. The university agreed to participate in the project and then announced this agreement. The project was thus a "topdown" decision that violated the traditional route of campus decision making, wherein the faculty have at least the perception that they have input into the decision-making process. As one faculty member said:

The whole possibility of doing this came about in a kind of entrepreneurial effort. ... And, the senior administrative decisions had to be made quickly. There was really not the time to go through the faculty and have all the committee meetings, and all of the four, and six, and twelve hour debates that usually ensue. But what happened is that when it was brought forward to the faculty, it was brought forward in a way which I and a number of members of the faculty conceived as "This decision has already been made. Why are you asking us?

Many faculty still resent the fact that the university made a commitment to the project without prior faculty approval.

The other major difficulty Brown has had to deal with is a lack of coordination not only in regard to the Scholar's Workstation project but also to computerization in general. Although the Academic Computing Center and IRIS seem to have cooperated well, there has been a general perception that the roles of each have been confused. Neither faculty nor staff is sure exactly what each unit is responsible for, and there still appears to be some overlap in the responsibilities of each.

In an attempt to provide some campuswide coordination of computing, a vice-provost of computing was appointed in the fall of 1985 . It was evident that expectations about what this individual would be able to accomplish were extremely high. Many of the individuals interviewed used the term Superman in describing the attributes the vice-provost would have to possess in order to complete the tasks he would be expected to undertake. Unfortunately, the first viceprovost of computing left after only a few months in the position. Another has recently been appointed, but the task of coordinating computer resources at Brown is an immense challenge and one that has not been achieved as yet.

Brown seems to be coming slowly to the realization that the Scholar's Workstation project will never be implemented fully in the form originally envisioned. One faculty member put it well:

There is a lot of joking around about these machines which people have which are not the machines that people are going to have which they may never have. I think at some point, someone is going to have to say that what [the project] was or turned out to be was a catalyst for a different kind of thing. And I haven't heard anyone say that yet.

By fall 1986, there were a small number of Scholar's Workstations on the campus with more expected for the spring semester, but the grand vision originally set out in 1983 of 10,000 workstations on campus will never be achieved. The workstation project presented a concept-a vision of the future. Brown has moved and will move still closer to that vision using a mixture of both existing technology and the workstations. Like any innovation, a group of true believers at Brown seized the initiative and began to implement change. Their efforts, although not yet successful, have changed the direction of the campus forever.

\section{Present and Future Impact on the Brown Library}

Although the Scholar's Workstations are not yet operational, the libraries at 
Brown have, like the rest of the institution, been affected by the attempt to computerize the campus. Here, too, the Scholar's Workstation project has served as a catalyst to promote change. The Brown libraries are already serving a highly computerized, "wired" campus, and they are preparing to serve an even more computer-oriented campus in the future. There is an air of expectancy in the library, and many of the librarians interviewed remarked that Brown was an exciting place to be working. For instance:

One of the most exciting and opportunistic things for librarians here at Brown is that expectations are very high all over campus that something different is going to happen and it is going to reach the library. ... It is going to affect everyone because the library is a part of it. ... I wouldn't want to be anywhere else. It is super to be a part of this.

Many of the librarians at Brown have been actively involved in planning for the Scholar's Workstation project. The university librarian, Merrily Taylor, has had a major role in the project since her arrival on campus in 1982. Other librarians have also been involved. For instance, the systems librarian serves on the executive board of IRIS. The librarians reported that before they became involved in the planning there were many unrealistic assumptions and misconceptions about the library. For instance, one person remembered a statement in one of the first planning documents that said the whole library could be put on a disk for the cost of a B1 bomber. Various members of the staff, under the guidance of Merrily Taylor, have been able to correct major misconceptions. The library's online catalog committee has worked closely with the Academic Computing Center (ACC) in developing plans for implementing the online catalog. And finally, there have been good contacts between the head of IRIS and the library.

Cooperation between the library, IRIS, and the ACC appear to be strong, with in- dividuals in each unit showing respect for their colleagues. The Scholar's Workstation project has helped bring about the realization that all elements in a wired university are interconnected. As one librarian stated:

The Library first started looking at the idea of an online system in '76, and at that time, we had no relationship with the computer center at all, and they weren't doing much on the rest of campus. . . . It would be our computer and our system. We went ahead and did something that just existed in the library. Now there's not only the computer center but a number of computer related groups on campus and they are interested in plugging the library into what they are doing. They recognize that if you are going to connect up the whole campus, everyone does want to plug into the library.

Ideally, in a "wired" university, where technological innovation is affecting instruction and research, the library would be at the center of this activity. Happily, this appears to be so at Brown. Surveys of the faculty and students show that access to library holdings through the workstations is a top priority.

The library has taken measures to ensure this access. It sought and was awarded a \$1.5 million grant from the Pew Memorial Trust to cover the cost of implementing the online catalog. Brown has purchased the BLIS system from BiblioTechniques and hopes the online catalog will be operational by fall 1987.* One of the most attractive features of the online catalog is its ability to integrate with the network of workstations. Any terminal or workstation connected to BRUNET would have dial access into the catalog. Planning is also under way to link the catalog to the Research Libraries Information Network (RLIN).

With the start-up of the online catalog, the library will have the first operational system on the network. All the academic administrators we spoke to recognized the importance of the library to the project. There is no doubt that the Pew Grant increased the importance and visibility of

\footnotetext{
*Although Biblio-Techniques has encountered financial difficulties in the past few months, it is not expected that this will cause the schedule for the online catalog to be delayed greatly.
} 
the library to many at Brown.

The library is also central to the workstation concept because it provides a use for the workstation that is extremely attractive to many who otherwise might not see its applicability to themselves and their research. As one senior administrator said, "We saw the library as a key to the humanistic use of the workstations. That was always in the back of our mind."

The library was described by several of the senior administrators as being one of the driving forces behind the workstation project. They see the library as an organization in the process of being changed into a much more important source of information, both in traditional and electronic forms. The administrators who have worked most closely on the workstation project envision the library becoming more and more dependent on computer technology:

The librarians, whether they know it or not, are going to be running, probably in a very short time, a computer system larger than what the university had two years ago. I was joking with them last night. I showed a picture of the entire Brown central computing facilities two years ago, and I said, this is what the library is going to have to look like in terms of their part [of the workstation project].

The online catalog is going to be just the first of a number of library services that faculty and student will want on their workstations. The library is starting to explore the direction it might go in providing access to online databases through the workstations. At an earlier stage of planning, there had been the expectation that the library might purchase and locally mount databases such as ERIC and Chemical Abstracts. The realization of the costs and the complexities of locally mounting such databases has put that notion on hold. However, laser disks or CD-ROM may ultimately provide a method of providing local access to commercial databases.

The library has begun to experiment with acquiring some databases. For instance, it recently purchased a crystallography database. The library, at the request of the provost, is developing a database policy for the university that will deal with items such as security, access, and acquisition of databases. There is also the expectation that scholars will soon want to download portions of larger databases and construct their own. What unit on campus will act as a consultant in helping create such databases and who will coordinate them? How will copyright be protected? None of these questions has been answered, but they are all being raised. It is expected that the library will play a key role in these discussions.

The librarians are concerned about more mundane changes that will likely occur as a result of the opening of the online cata$\log$. For instance, the librarians who work in the government documents department and the rare book libraries expect more use of their materials once records are entered in the online catalog and more people are made aware of their holdings. There is also concern that patrons may have expectations about the online catalog that cannot be met. For instance, one special collections librarian stated:

If it works out as it is visualized, they [patrons] will have greater access. . . it is going to create a delivery problem. There should be a great deal more activity, possibly more than we can handle, initially. . . an expectation to say since we search it electronically, and probably reserve it and check it out electronically, that eventually they are going to want us to transmit it to them electronically so that they may never leave their terminals. ... We'd never be able to transmit. Rare books is not going into electronic publishing.

It is to the library administrators' credit that they have consistently sought not to raise the expectations about the online catalog. The library has not, for example, wanted to "fill the newsletter with articles about the online catalog because we don't want people expecting it around the corner." The information provided has been understated and has stressed only the elements of the catalog that will be available immediately. But many fear that what has been done with the online catalog is similar to what has been done with the workstations; people's expectations have been raised, and some will expect all the enhancements from the very beginning.

It is clear that the online catalog will lead 
to changes in the staffing of the library. It is foreseen that the library will need to extend its hours or, at least, have some help available to users in hours the library is closed.

If your online catalog is up at 2 or $3 o^{\prime}$ clock in the morning and you have a student in a dorm or a faculty member who is up at that hour trying to do something and they need help, who are they going to call? ... Who's going to do the night duty? Whose phone number are we going to give to people who want help in the middle of the night?

There is also an awareness that the staff will need to devote more time to instruction of patrons, initially in the use of the online catalog and, later, in various databases.

The majority of librarians interviewed agreed that the technical services/public services lines at Brown were becoming more blurred. The technical services division will assume an increasing educational role with the implementation of the online catalog. Most, however, felt that the traditional division would remain in place, at least in the near future.

It is also recognized that the next logical step after the online catalog becomes a reality is the creation of a document delivery system. The faculty were uniformly enthusiastic about the possibility of having the items located on the online catalog delivered to them. The librarians recognize the need for a document delivery system, but the logistics of such a system have not yet been worked out.

Another intriguing possibility that arises in connection with the institution of a document delivery system is that the social role of the library might change on an electronic campus. At this time, the Rockefeller Library (central library) is a social gathering place. Students congregate there to study because it provides access to needed library materials and to other students. Some have speculated that the electronic campus may allow libraries to relinquish the study-hall role they play on so many campuses. Both faculty and librarians doubt that this will happen at Brown. It is expected that for those faculty who are "comfortable and skilled at using the catalog from a remote location and have somebody to pick up the material or a delivery service, there may be less physical use of the library." But for many faculty and most students, the library will still be the place to go not only to mingle with others but also to receive personalized help in using the information available. There seems to be agreement with Naisbitt's ideas on the need for a "high tech-high touch" combination. ${ }^{6}$

There is much concern about what may happen to the library's budget in the coming years. Librarians see a threat arising not only from the diversion of funds from the library to pay for overall campus computerization but also an internal threat as more of the library's funds have to be devoted to electronic information sources at the expense of traditional acquisitions. The Brown libraries went through two lean decades, the 1960 s and 1970 s. The librarians still feel that a great deal of catching up has to be done, and the prospect of a less-than-adequate book budget is especially upsetting to those librarians working in the collection development area:

I feel that we already have spread so many resources, so thin, that I hope it is not a house of cards, and it will all come falling down, because I see the library as a strong supporter of the computer, and it would be more than upsetting to me, if the support didn't come back. I'm not sure the jury is in.

and:

For the next 10 or 12 years, the electronic costs are going to continue to escalate. It may be, since all budgets are reasonably finite in universities, that the proportions that are devoted to the more traditional acquisitions may suffer. . . . If there is separate outside money as there has been, and, hopefully, continues to be, the impact will not be as great, but it is still going to be there.

It seems likely that the library will, in the absence of a large increase in its budget, have to devote a greater percentage of the budget to electronic information sources. Given the general problems with financing computerization at Brown, it would also appear highly unlikely that the library's budget will increase significantly.

One senior university administrator assured the interviewers that the library budget had not been affected by the Scholar's Workstation project. "The question is where it (money for computeriza- 
tion) comes from, and we have not attacked the library. It has come from other discretionary sources." But there is definitely a sense that the library and the computerization project may soon be competing for the same funds. As another senior administrator remarked:

We haven't had a situation here where there is a concrete next step to move the faculty workstations program ahead, and there is a concrete next step to do in the library, and they both cost half a million dollars, and you can't do both together. I think that sometime in the future, before the decade is out, that we will probably have it.

The librarians are aware of the possible threats to their budgets and realize the need for creative funding (i.e., more outside money) and more productive networking with other systems.

Considerable thought is also being devoted to whether it will be possible to go on providing all library services without charging patrons. Currently, Brown charges students and faculty for online computer database searching, but at a subsidized rate. There is a great resistance on the part of most librarians to charging students directly for other library services, especially since it already costs approximately $\$ 15,000$ a year to attend Brown. Their strong preference is to insure that all students have access to the information they need without regard to their ability to pay. Whether this resolve can be maintained at Brown has yet to be decided.

Clearly, the changing role of the library raises the question of whether a merger of the library and the computer center might be expected, and individuals in both have begun to perceive common areas of interest. Curiously, there was a greater inclination for those who worked outside the library to see such a merger as likely than for those who worked in the library itself. One individual who works in the computer center stated:

I see them as merging. I suppose if I wanted to play prophet, I could pick a year, but that doesn't seem useful. ... I am going to make two assumptions. The first is that over the next few years a higher and higher percentage of what people are looking for is going to be found in electronic indices. And, if they do retrospec- tive conversion, eventually nearly everything people are looking for is going to be found electronically. Secondly, I think that more primary sources are going to be found electronically on videodiscs, over national or international networks or some might be mounted locally. As these two things happen, we are going to merge.

This individual went on to sketch a lengthy scenario of the role of the "compu-librarian" in the campus of the future.

The university administrators recognize the difficulties inherent in merging the two functions. One stated:

The problem is librarians are not trained ... very much in terms of understanding and using electronic forms although they are open to them. Computing people, information services people have no real appreciation of libraries. So bringing the two together, even with two people with good will and controllable tempers. . . it's going to be a long time.

The implication was that it would be a lengthy process. The merger of the ACC and the library is likely, but probably not in the near future. The outside researchers feel that the strength of the library staff and administration at Brown bode well for the library in case of such a consolidation.

In summary, the library at Brown sees itself as caught up in the process of innovation. It is clear that the technological innovation related to the network of scholar's workstations (regardless of their ultimate configuration) will have a profound impact upon the library. The effects are beginning to be felt now. The new information technologies are requiring the university and the library to rethink how scholarly information should be provided and accessed on campus. The process is still in its beginning stages, but the Brown experiment gives us the opportunity to watch an institution invent the appropriate structure for the provision of information in a "wired" university.

\section{Lessons to be Learned from Brown}

For all those libraries whose institutions are just beginning to explore extensive computerization of the campus, there are some lessons that can be learned from the Brown experiment. Needless to say, the experiences of one institution cannot be 
transferred to another, and each institution will have a distinctive pattern in its acquisition of electronic technology. Nonetheless, some of the things that have been learned by the librarians at Brown can be used by other institutions. All individuals interviewed were asked what they would tell people at another institution contemplating a venture similar to Brown's. There was some uniformity in their responses. None of the responses were very original, but, to the individuals interviewed at Brown, it was still advice worth repeating.

One common element that was stressed over and over again was the necessity of adequate planning. Many others spoke about the need to create and nurture a healthy climate of change within the institution and to realize that change, especially technological change, is extremely threatening to staff members.

Everyone mentioned the critical role of communication: "You can't overcommunicate." Be sure that it is regular and consistent throughout the process and that all members of the staff are included.

Don't raise expectations too high. The Scholar's Workstation project at Brown has brought home that lesson. The voices were loud and clear: "Don't promise what you can't provide" and "Don't oversell in hopes of convincing people." Remember to put heavy emphasis on a transition period; not everything is going to work immediately, and not everything will be included from the beginning.

Finally, many individuals said to re- member "that Murphy will get you, every time." You cannot plan for all problems, but they should be expected at every turn. Remember too, that when you work with outside vendors, they will have a plan or cycle of their own that may not coincide with yours. Therefore, it is necessary to be as flexible as possible. There is always a need for contingency plans. They tend to sharpen the main plan and allow for shifts without undue upset.

Every institution is not going to be an innovator, and, indeed, most should not be. The few that have the institutional resources, expertise, and freedom to experiment perform a useful service for the rest. The non-innovating majority can learn both from the successes and the failures of the pioneers. The verdict is still out on the Scholar's Workstation project, and it will be several years before an accurate assessment can be made on its real impact. At this time, it appears that the project itself may not be the success that was expected, but that, paradoxically, the side effects generated may have succeeded in transforming Brown along the same lines envisioned by the project's planners.

Ultimately, it seems the critical elements in the process were the emerging concepts about the educational uses of computers in higher education, not the specific technology itself. The Brown experiment exists as an exciting opportunity for other institutions to study and to adapt variations of it to their own needs, as quietly and with less publicity, they too become "Star Wars" universities.

\section{REFERENCES}

1. Marc S. Tucker, ed., Computers on Campus: Working Papers, AAHE Current Series in Higher Education, no.2 (Washington, D.C.: American Assn. of Higher Education, 1983-84), p.2.

2. William S. Shipp, "The Scholar's Workstation Project at Brown University," photocopy.

3. Tucker, p.16.

4. Maurice Glicksman, "Memorandum to Members of the Faculty," May 31, 1983, photocopy.

5. Glicksman, "Memorandum to Members of the Faculty"' July 12, 1983, photocopy.

6. John Naisbitt, Megatrends: Ten New Directions Transforming Our Lives (New York: Warner, 1982), p.39. 